\title{
Perceptions of the Etiology and Treatment of Hypertension Among Some Traditional Healers in Cameroon
}

\author{
Jean Meli ${ }^{1}$, Benedicta N. Nkeh-Chungag ${ }^{*}, 2$, Jean Gerard Doumtsop Tatou ${ }^{1}$, John Simo Mope ${ }^{3}$ and \\ Samuel Kingue ${ }^{3}$ \\ ${ }^{I}$ Department of Public Health, Faculty of Biomedical Sciences, University of Yaoundé I - Cameroon (JM and J-GDT) \\ ${ }^{2}$ Department of Physiology, Faculty of Health Sciences, Walter Sisulu University, PBx1. Mthatha 5117, South Africa \\ ${ }^{3}$ Department of Cardiology, Faculty of Biomedical Sciences, University of Yaoundé I-Cameroon (JSM and SK)
}

\begin{abstract}
Objectives: To investigate the perceptions of the etiology and treatment of hypertension among a number of traditional healers reputed to treat the disease in Yaoundé.

Methods: Semi-structured interviewer-administered questionnaires were administered to 30 selected participants to collect information. Data were collected within the consulting rooms of the traditional caregivers.

Findings: Most traditional health caregivers thought that hypertension was associated with target organs such as the heart, brain, liver and kidneys. Over $23 \%$ of participants used modern equipment to diagnose the disease or sent their patients to western hospitals for diagnoses before recommending treatment. However, close to 5\% of our participants used mystical methods to diagnose hypertension in their patients. Importantly, all traditional healers depended on the patients' testimony or physical appearance to determine treatment success.

Conclusion: The tools and methods used by many traditional healers to diagnose hypertension are inadequate. Treatment endpoints fail to recognize the need for the long-term management of hypertension.
\end{abstract}

Keywords: Traditional healers, hypertension, perceptions, beliefs, symptoms.

\section{INTRODUCTION}

Traditional healers are widely accepted as alternative healthcare providers in most sub-Saharan communities [1]. They are part of the local community and function within a specific community (whose culture is well known to them) though their fame and success may spread their popularity to other tribes. This is because every tribe has its own perception, believes and healing methods applicable to health and disease [2] which can be explained by the fact that the practice of traditional medicine is deeply rooted in the culture and religion of most African tribes [3]. They are often first consulted in case of sickness and only those who are not satisfactorily treated go to western health services [4]. Traditional healers are therefore an important link between the people (especially those living in rural communities) and primary health care services [5].

In Cameroon, like in other developing countries, perceptions of health and disease are related to rural or urban dwelling and secondly to the socio-economic status of the individual [6]. In many rural communities access to western

*Address correspondence to this author at the Department of Physiology, Faculty of Health Sciences, Walter Sisulu University, PBx1. Mthatha 5117, South Africa; Tel: (+27) 475022794 / (27) 726373725; Fax: (+27)502 2758; E-mail: bnkehchungaga@wsu.ac.za hospitals is not readily available, this makes the traditional healers the care givers of choice [7]. Indeed, it is reported that more than $80 \%$ of Africans, including Cameroonian, make use of one kind of alternative therapy or the other from traditional healers [8]. Current WHO reports show that there is an increasing trend across the world for the use of traditional and alternative medicines [9]. Importantly, the Cameroonian local government is beginning to acknowledge the role of healers in health care delivery, whose decoctions and concoctions are either used alone or in combination with western therapy [10].

Folk model of illness and diagnostic methods are however based on oral traditions [11] which are believed to have more of a supernatural than natural cause. Importantly, communication between the traditional health providers and their patients is very deep. The former spends much time listening to his patient and discussing the causes of the disease and the course of treatment with the patient. This makes the patient feel well taken care of and involved in his treatment - a factor which is often lacking in the local western hospitals and clinics [12]. Consequently, patients tend to consult the traditional healer even while on western medication.

Despite the popularity of traditional healers, the biomedical health practitioner views the perception and treatment of various diseases by traditional healers as being 
Table 1. Demographic Characteristics of Participants Studied

\begin{tabular}{|c|c|c|}
\hline \multicolumn{2}{|c|}{ Characteristics } & \multirow{2}{*}{$\begin{array}{c}\text { Participant Information } \\
30\end{array}$} \\
\hline \multicolumn{2}{|c|}{ Total Number of participant } & \\
\hline Gender & Females & $20 \%$ \\
\hline \multirow{2}{*}{ Age (years) } & Median age & $41.5 \mathrm{y}$ \\
\hline & Maximum age & $70 \mathrm{y}$ \\
\hline \multirow[b]{3}{*}{ Provinces of origin } & Western Province & $57 \%$ \\
\hline & Northwest Province & $17 \%$ \\
\hline & Northern Province & $13 \%$ \\
\hline Religion & Muslim & $36.7 \%$ \\
\hline
\end{tabular}

unscientific [10]. The aim of this study was therefore to investigate the perception and beliefs of local traditional healers on hypertension in the Yaoundé urban area.

\section{METHODS}

Yaoundé is the second largest city in Cameroon - a country with a population of just over sixteen million inhabitants and an annual growth rate of $2.36 \%$ [13]. This city was chosen for our study because it is expected that with the many more modern primary health care facilities, the need for traditional healers would be less compared to the smaller towns. This study made use of a quantitative and descriptive approach. The field work was carried out in two stages. The first phase involved the identification of traditional healers registered with one of the traditional healers associations in Yaoundé. Our study targeted those who claimed to be able to diagnose and treat hypertension. Using these criteria we selected 34 traditional healers though only 30 of them were willing to participate in the study. The second phase involved focused interviews using semistructured open questionnaires. All identified healers gave signed consent to participate in the study after having received a detailed explanation of the study design. Ethical approval for this study was obtained from the Faculty of Biomedical Sciences - University of Yaoundé ethics committee.

Participants were observed at work in their consultation rooms (which are usually in their homes) for three days in order to get acquainted with how they operate. This was followed by the administration of the questionnaire. The

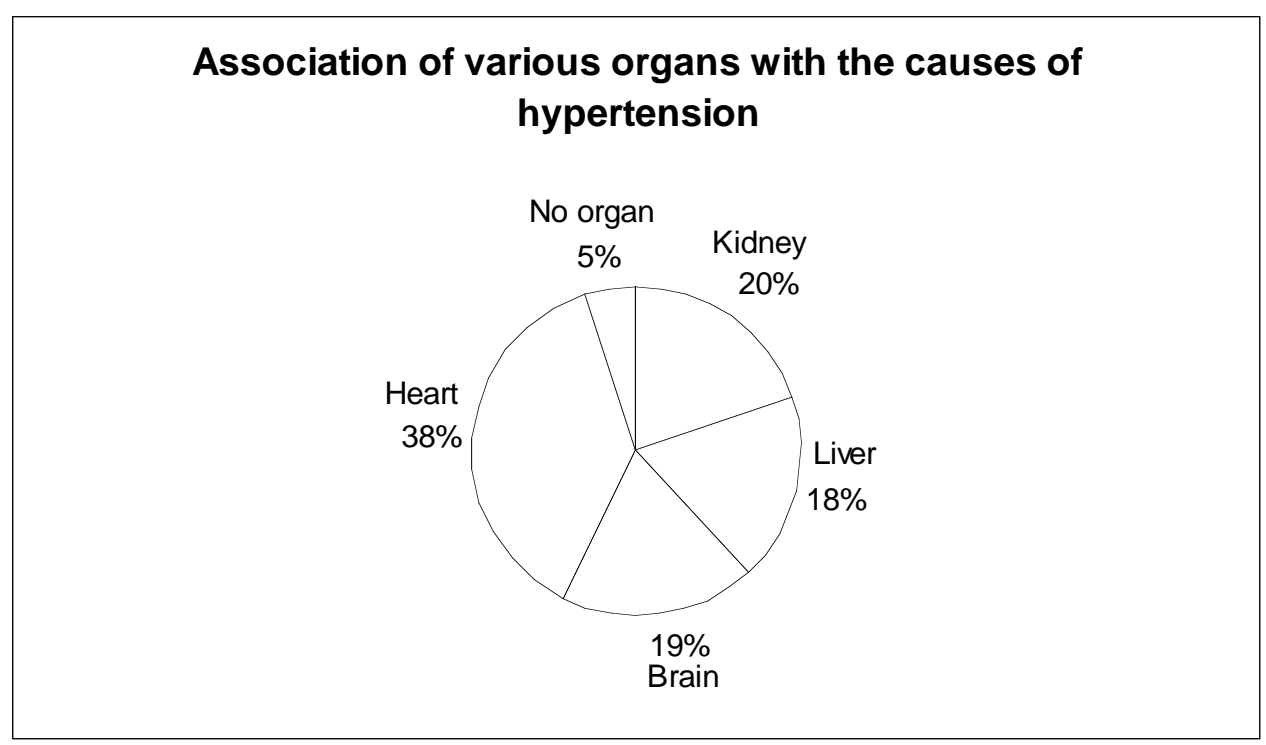

Fig. (1). Perceptions of organ involvement in the etiology of hypertension among traditional healers. 
questionnaire was conceived around five main aspects concerning their perception of hypertension with respect to diagnosis, identification of involved target organs, predisposing or risk factors, treatment methods and evaluation of response to treatment.

\section{RESULTS}

The study findings showed that traditional healers were both males and females though many more were males. The women were more involved in the seer part of the healing which involved mysticism. Interestingly, traditional healers tended to be in their forties though there were a few old men as well. Most traditional healers in this study were from the West and North West provinces of Cameroon, although a few were non-Cameroonians. It was important to note that both Christians and Muslims practiced as healers (Table 1).

However, with respect to the possibility of organs being involved in the etiology of hypertension, most of the traditional healers agreed that the heart was involved while others thought the kidney, liver and/or brain were involved as well. A smaller group (5\%) did not think that any organ was involved at all, this group thought non-organic causes were responsible for its etiology (Fig. 1).

The perception of risk factors and possible causes of hypertension were diverse. About $90 \%$ of the practitioners thought hypertension was associated with negative emotional states, though stress, genes, excess work and aging also ranked high (Table 2). Some participants (30\%) thought that hypertension had purely non-physical causes such as witchcraft, the displeasure of the ancestors and non-respect of traditional rites.

When asked about their view of how hypertension was diagnosed, less than $24 \%$ of participants knew for sure that there is an instrument for the diagnosis of hypertension or measurement of blood pressure. Of those who were aware of the use of diagnostic tool, an even smaller fraction $(13 \%)$ owned and knew how to use a sphygmomanometer to measure blood pressures. The other $11 \%$ sent their patients to hospitals for proper diagnoses before instituting treatment. The greater majority of traditional healers diagnosed the presence of hypertension by the presence of a combination of presenting symptoms. A small number of healers neither used an instrument nor presenting symptoms but depended on mystical methods for diagnosis (Table 3 ).

All patients were always able to afford the prescribed traditional drugs and were compliant with the treatment regimen. Patients were required to take these medications two or three times per day depending on the type of preparation. Many healers recommended prayers to the ancestors and whatever deity the patient worshiped. Importantly, diet and physical exercise were recommended as part of management. However, for some practitioners, treatment necessitated spiritualistic rites which were of particular importance for the traditional healers who believed hypertension to result from non-respect of traditional rites (Table 4).

The disappearance of symptoms and an improved physical appearance as assessed by the traditional healer

Table 2. Perceptions of the Risk Factors for Hypertension

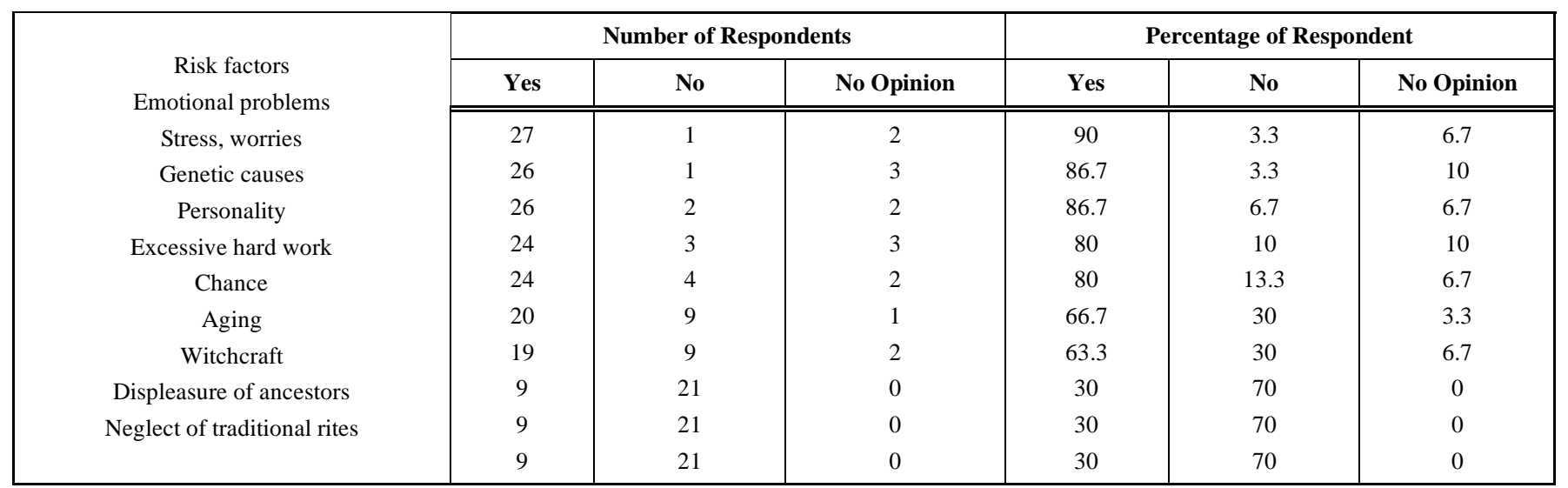

Table 3. Tools and Methods Used to Diagnose Hypertension

\begin{tabular}{|c|c|c|}
\hline Diagnosis of Hypertension & & \% of Respondents \\
\hline \hline \multirow{2}{*}{ No knowledge of any diagnostic tool } & Presenting symptoms only & 70 \\
\cline { 2 - 3 } & Mystical methods & 6.7 \\
\hline \multirow{2}{*}{ Knowledge of some kind of diagnostic } & Owned and used a sphygmomanometer & 13.3 \\
\cline { 2 - 3 } & Used hospital for diagnosis & 10 \\
\hline
\end{tabular}


Table 4. Types of Treatment Prescribed by Healers

\begin{tabular}{|c|c|}
\hline Recommendation & \% of Traditional Healers \\
\hline \hline Drugs (plant concoctions or decoctions) & 100 \\
\hline Prayers & 86.7 \\
\hline Diet & 80 \\
\hline Physical Exercise & 80 \\
\hline Changing of homes & 30 \\
\hline Traditional/ spiritualistic rites & 49 \\
\hline
\end{tabular}

were considered as independent indicators of a successful treatment. The patient's feeling of wellness was also considered as successful treatment endpoints (Table 5). Some traditional healers relied on blood pressure values measured in the hospitals while those who had learned how to use the sphygmomanometer did the measurements themselves. If the obtained blood pressure values were within the normal range, the patient was declared healed of hypertension.

Table 5. Treatment Endpoint Determination

\begin{tabular}{|c|c|}
\hline Determination of Healing & \% Healers Making Use of it \\
\hline \hline Disappearance of symptoms & 100 \\
\hline $\begin{array}{c}\text { Blood pressure values (Use of } \\
\text { sphygmomanometer) }\end{array}$ & 66.7 \\
\hline Physical appearance & 100 \\
\hline Patient's declaration & 100 \\
\hline
\end{tabular}

\section{DISCUSSION}

In this study we looked at how traditional healers diagnose, treat and determine treatment endpoints for hypertension. The traditional healers play an important role in the health care of Cameroonians: both rural and urban dwelling [7]. They provide support and solace to their patients which are often lacking in the western hospitals. Traditional healers take time to give their patients an understanding of the cause(s) and course of treatment of their diseases [14] which are rarely provided by trained medical practitioners.

The distribution of traditional healers is reflective of the commitment of the people of these provinces to traditional medicine. Although the Eastern province is reputed for good traditional medicine practices and clairvoyance none of the participants in this study was from that part of the country, possibly because the pygmies do not like moving away from the forest to more urbanized centers [15]. We noted a trend from older to younger people involved in this trade. This may be as a result of the socioeconomic demands on families' causing younger persons to learn the trade and for shorter periods. Not having the experience and fame of their trainers (older healers), they moved away from their local communities to more urban areas where they could practice freely. Another reason may be the greater availability of clients who can pay for their services and remedies promptly thus providing a sustainable business activity for the healers.

Each healer's perception varied with his experience and socio-cultural background. Healers tended to be more objective about the causes of hypertension depending on their age and place of origin. The younger traditional healers associated the disease less with mystical influences while those from the western province particularly tended to associate the disease with failure to satisfy the ancestors or the involvement of some supernatural powers. To this group, hypertension was not the result of stressful living conditions as well as genetic factors but due to some non-physical causes.

Although witchcraft and failure to perform traditional rights did not rank high as a possible cause of hypertension, yet it constituted an important element in the treatment of the disease, indicating that many traditional healers often think of the cause of the disease beyond organic causes. Yaoundé being an urban centre with most of its traditional healers being themselves quite young and not having had sufficient time to learn all about the trade or were uninterested in the mystical part of it, justifies this low level of involvement with the mystical. Moreover, the younger healers tended to be more objective about the possible causes of hypertension, a fact which might be explained by their greater exposure to modern hospital practice. A handful (13\%) of the traditional healers both owned and knew how to make use of a sphygmomanometer for the diagnosis of hypertension. Others sent their patients to hospitals for proper diagnosis, indicating that they acknowledge the need for modern techniques to help with diagnosing their patients in an objective manner.

Traditional healers do not charge consultation fees, thus making them readily approachable not only by those who cannot afford the cost of hospital fees, but also by those who want a support system as they go through chronic treatment in hospitals. They provided drugs for treatment in all cases even though drug therapy was not used alone but always in association with a plethora of other things. Unlike hospital, traditional healers provided medication at daily retail rates for patients who could only afford it as such. Of note was the tendency to prescribe lifestyle changes which were beneficial to the patient. However, the dependence of a successful treatment on the patients testimony, failed to recognize the fact that hypertension has to be managed for a life time. The healers viewed hypertension like a simple infection which could be treated by antibacterial therapy. This pointed to a lack of knowledge on the causes and proper management of hypertension as well as the progression of the disease.

Many Africans either make use of only traditional medicines or combine these with modern drugs. This trend has caused several governments in developing countries to make attempts to integrate traditional medicine into their primary health care systems [16,17], although mainstream medical practitioners are skeptical of the outcome $[18,19]$. This is probably due to the lack of knowledge of how most traditional healers work and what they have to offer in the treatment of diseases [20] and concerns about the toxicity of the plant extracts used. The present study underscores some of the concepts, perceptions and knowledge of hypertension in traditional African medicine. Whereas in modern medi- 
cine the symptoms and causes of hypertension are standard and clearly known, in traditional medicine they are very subjective [21] and depend on the traditional healer's society, experience, personal convictions and exposure to modern medical practice.

Traditional healers have been and will continue to be health care providers for the majority of Cameroonians as the economic crisis deepens. Therefore, to make their contribution to the management of hypertension beneficial, local healers have to receive basic training in pathology and diagnostic methods and assessment of treatment outcomes of hypertension. A greater exposure of traditional health care givers to modern hospital practice will greatly improve their contribution to the health care they offer to their communities.

\section{REFERENCES}

[1] Tabi MM, Powell M, Hodnicki D. Use of traditional healers and modern medicine in Ghana. Int Nurs Rev 2006; 53: 52-8.

[2] Jian S, Agrawal S. Perception of illness and health care among Bhils: a study of Usaipur district in southern Rajasthan. Stud Tribes Triabals 2005; $3: 15-9$.

[3] Pinkoane MG, Greeff M, William MJ. The patient relationship and therapeutic techniques of South Sotho traditional healer. Curationis 2005; 8: 20-30.

[4] Barker RD, Millard FJ, Malatsi J, et al. Agarawal SDE Valiere S. Traditional healers, treatment delay, performance status and death form TB in rural Soth Africa. Int J Tuberc Lung Dis 2006; 10: 6705 .

[5] Nelms LW, Gorski J. The role of the African traditional healer in women's health. J Transcult Nurs 2006; 17: 184-9.

[6] Ompad DC, Galea S, Caiaffa WT, Vlahov D. Social Determinants of the Health of Urban Populations: Methodologic Considerations. J Urban Health 2007; 84: 42-53.
[7] Tembong AC. Health care providers choice: the North West province of Cameroon. Int J Health Plann Manage 1996; 11: 53-67.

[8] Nyika A. Ethical and regulatory issues surrounding African traditional medicine in the context of HIV/AIDS. Dev World Bioethics 2007; 7: 25-34.

[9] Hillenbrand E. Traditional-conventional medicine collaboration: perspectives from Cameroon traditional practitioners. Nordic J Afr Studies 2006 15: 1-15.

[10] WHO Traditional Medicine Strategy 2002 - 2005. World Health Organization. Geneva 2002.

[11] Report 13 of the Council on Scientific Affairs (A-97). [cited 2007 February 14] Available from: http://www.ama-assn.org/ama/pub/ category/13644.html

[12] Veena Bhasin. Sickness and therapy among tribals of Rajasthan. Stud Tribes Tribals 2003; 1: 77-83.

[13] Cameroon Population. [cited 2007 February 13] Available from: http://www.historycentral.com/NationbyNation/Cameroon/populati on.html

[14] Berenzon-Gorn S, Ito-Sugiyama E, Vargas-Guadarrama LA Diseases and illness for which help is sought from traditional healers in Mexico city. Salud Publica Mex 2006; 48: 45-56.

[15] Colin MT. The Mbuti Pygmies: an ethnographic survey. NY: American museum of national history 1965; pp. 139-282.

[16] Sharma D. India to promote integration of traditional and modern medicine. Lancet 2001; 358: 1524.

[17] Spotlight on Traditional Medicine. [cited 2007 March 6] Available from: http://www.scidev.net/dossiers/index.cfm?fuseaction= specifictopics\&dossier $=7 \&$ topic $=147$

[18] WHO: Regional Committee seeks integration of traditional medicine in health services. [cited 2007 March 6] Available from: http://www.wpro.who.int/NR/exeres/B9926838-D583-4B56-A979195C8BBEE794.htm

[19] Mudur G. Indian doctors decry proposal to teach traditional medicine. BMJ 2001; 323; 1090 .

[20] Gessler MC, Msuya D, Nkunya MH, Heinrich M, Tanner M. Traditional healers in Tanzania: the perception of malaria and its causes. J Ethnopharmacol 1995; 48: 119-30.

[21] Tierra M. A Comparative Evaluation of Diagnostic Systems used in Herbal Medicine. [cited 2007 March 6] Available from: http://www.planetherbs.com/articles/diagnosis.html 